\title{
The Delphi Method as a Research Tool: An Example, Design Considerations and Applications
}

Information \& Management

Volume 42, Issue 1, December 2004, Pages 15-29

http://dx.doi.org/10.1016/j.im.2003.11.002

\author{
Chitu Okoli ${ }^{1}$ \\ John Molson School of Business \\ Concordia University, Montréal, Canada \\ Suzanne D. Pawlowski \\ Department of Information Systems and Decision Sciences \\ Louisiana State University, Baton Rouge, USA \\ Original paper sent 21 May 2003; Request for change 12 July 2003; \\ Accepted with modification 8 November 2003
}

Section: Techniques

\begin{abstract}
The Delphi method has proven a popular tool in information systems research for identifying and prioritizing issues for managerial decision-making. However, many past studies have not adopted a systematic approach to conducting a Delphi study. This article provides rigorous guidelines for the process of selecting appropriate experts for the study and gives detailed principles for making design choices during the process that ensure a valid study. A detailed example of a study to identify key factors affecting the diffusion of e-commerce in Sub-Saharan Africa illustrates the design choices that may be involved. We conclude with suggestions for theoretical applications.
\end{abstract} commerce

Keywords: Delphi method; Group decision making; Research design; Strategic planning; Electronic

${ }^{1}$ Corresponding author.

Mailing: 1455 boulevard de Maisonneuve Ouest, Montréal, Québec H3G 1M8, Canada

E-mail address: Chitu.Okoli@concordia.ca; Phone: +1 (514) 848-2424 


\section{Introduction}

The Delphi method has proven a popular tool in information systems (IS) research [4,6,13,14,16,24,25,35]. Citing "a lack of a definitive method for conducting the research and a lack of statistical support for the conclusions drawn," Schmidt [34] presented a stepwise methodology for conducting such studies. Building on the framework that Schmidt developed, we offer two contributions towards increasing the value of Delphi studies in investigating research questions. First, we fill in many details in the context of Schmidt's framework by providing guidelines on how to conduct a rigorous Delphi study that identifies the most important issues of interest by soliciting qualified experts. Second, we demonstrate how to use a Delphi survey as a research tool to serve a variety of different purposes in the theorizing process. Increasing the rigor will increase the confidence with which researchers can use the results in subsequent studies and managers can make decisions based on information gathered using these methods.

Bricolage is a French term that means "to use whatever resources and repertoire one has to perform whatever task one faces" [40]. Characterizations of the research process as bricolage and the researcher as bricoleur [10] serve to remind us of the improvisation and opportunism inherent in the research process and the need to put our research tools to multiple use. A third goal, then, is to encourage researchers to incorporate the Delphi method into their research repertoire and to suggest some of the various ways they could apply the method in the theorizing process.

\section{Overview of the Delphi method}

The Delphi method originated in a series of studies that the RAND Corporation conducted in the 1950's. The objective was to develop a technique to obtain the most reliable consensus of a group of experts [8]. While researchers have developed variations of the method since its introduction, Linstone and Turoff [17] captured common characteristics in this description:

"Delphi may be characterized as a method for structuring a group communication process so that the process is effective in allowing a group of individuals, as a whole, to deal with a complex problem.

To accomplish this "structured communication" there is provided: some feedback of individual contributions of information and knowledge; some assessment of the group judgment or view; some opportunity for individuals to revise views; and some degree of anonymity for the individual responses."

Delphi researchers employ this method primarily in cases where judgmental information is indispensable, and typically use a series of questionnaires interspersed with controlled opinion feedback [33]. A key advantage of the approach is that it avoids direct confrontation of the experts. Dalkey and Helmer observed:

"[The controlled interaction] appears to be more conducive to independent thought on the part of the experts and to aid them in the gradual formation of a considered opinion. Direct confrontation, on the other hand, all too often induces the hasty formulation of preconceived notions, an inclination to close one's mind to novel ideas, a tendency to defend a stand once taken, or, alternatively and sometimes alternately, a predisposition to be swayed by persuasively stated opinions of others." Researchers have applied the Delphi method to a wide variety of situations as a tool for expert problem solving. They have also developed variations of the method tailored to specific problem types and outcome goals (see Linstone and Turoff for a description of the evolution of the method). One variant that has received widespread use is the "ranking-type" Delphi, used to develop group consensus about the relative importance of issues. Schmidt provides a detailed description of how to conduct this type of Delphi survey, including guidelines for data collection, data analysis (based on nonparametric statistical techniques), and reporting of results.

Table 1 lists examples of studies that have used the Delphi method in information systems research. Forecasting and issue identification/prioritization represent one type of application of the method. The majority of the Delphi efforts during the first decade were for pure forecasting, including both short- and long-range forecasts. Follow-up studies (e.g., [1] and [28]) have demonstrated the validity and long-range accuracy of the Delphi 
technique. While most forecasting studies use Delphi to surface a consensus opinion, others such as the study by Kendall et al. [15] emphasize differences of opinion in order to develop a set of alternative future scenarios.

Concept/framework development represents a second type of application of the Delphi method. These study designs typically involve a two-step process beginning with identification/elaboration of a set of concepts followed by classification/taxonomy development.

Table 1

Applications of the Delphi method in information systems research

\begin{tabular}{|c|c|}
\hline $\begin{array}{l}\text { Application of } \\
\text { the Delphi Method }\end{array}$ & Example Studies \\
\hline $\begin{array}{l}\text { Forecasting and Issue } \\
\text { Identification/ } \\
\text { Prioritization }\end{array}$ & $\begin{array}{l}\text { - Brancheau et al. [4,5]_Purpose: Identify the most critical issues facing IS } \\
\text { executives in the coming 3-5 years. Participants: Senior IS executives } \\
\text { - Czinkota and Ronkainen [7]_Purpose: Forecast changes in the international } \\
\text { business environment over the next decade and the impact of these changes } \\
\text { on corporate practices. Participants: Experts from policy, business and } \\
\text { academic communities } \\
\text { - Hayne and Pollard [13]_Purpose: Identify the critical issues in IS in the coming } \\
5 \text { years perceived by Canadian IS executives and non-management IS } \\
\text { personnel and compare to global study rankings. Participants: IS personnel } \\
\text { - Kendall et al. [15]_Purpose: Forecast the role of the systems analyst in the } 21^{\text {st }} \\
\text { century. } \\
\text { - Lai and Chung [16]—Purpose: Identify a prioritized list of international data } \\
\text { communications activities vital to multinational corporations in managing } \\
\text { information exchanges for control and implementation of global business } \\
\text { strategies. Participants: IS executives } \\
\text { - Viehland and Hughes [39]—Purpose: Compile a ranked list of } 12 \text { future } \\
\text { scenarios related to the potential success of the Wireless Application Protocol } \\
\text { (WAP). Participants: Industry and academic experts }\end{array}$ \\
\hline $\begin{array}{l}\text { Concept/Framework } \\
\text { Development }\end{array}$ & $\begin{array}{l}\text { - Bacon and Fitzgerald [2]_Purpose: Develop a framework of the main areas of } \\
\text { the IS field. Participants: IS academics } \\
\text { - Holsapple and Joshi [14]_Purpose: Develop a descriptive framework of } \\
\text { elemental knowledge manipulation activities. Participants: Researchers and } \\
\text { practitioners in the knowledge management field } \\
\text { - Mulligan [24]_Purpose: Develop a capability-based typology of information } \\
\text { technologies within the financial services industry. Participants: Members of } 11 \\
\text { different organizations } \\
\text { - Nambisan et al. [25]—Purpose: Develop a conceptual taxonomy of } \\
\text { organizational design actions—mechanisms to enhance technology users' } \\
\text { propensity to innovate in information technology. Participants: Practicing senior } \\
\text { managers from diverse industries } \\
\text { - Schmidt et al. [35]—Purpose: Develop a ranked list of common risk factors for } \\
\text { software projects as a foundation for theory building about IS project risk } \\
\text { management. Participants: } 3 \text { panels of experienced software project managers } \\
\text { from Hong Kong. Finland and the United States }\end{array}$ \\
\hline
\end{tabular}




\section{Example research study design using the Delphi method}

Schmidt presented a guideline focusing on the major phases of the process and on analysis issues. However, the example we present in this paper focuses on perhaps the most important yet most neglected aspect of the Delphi method - choosing appropriate experts. This neglect is problematic, considering that most Delphi researchers characterize the technique as a method for soliciting information from experts. We based our guidelines primarily on those initially developed by Delbecq, Van de Ven and Gustafson [9]. Setting these principles in Schmidt's framework, we provided a more complete guideline for a rigorous approach towards conducting Delphi methods.

Because of the detail of our instructions, it would be difficult to discuss them abstractly. Thus, rather than trying to write generally for any Delphi investigation topic, we have used a specific concrete research project (soliciting experts for critical success factors for e-commerce in Sub-Saharan Africa) as a particular contextual illustration of how we would apply our methodology. Although the guidelines are set in a particular context, other Delphi researchers can readily adopt these principles for any other topic. We illustrate basic steps in the approach as well as some of the choices and selection criteria that may be involved at different points in the research design. For the purposes of exposition, we present the description of the design and rationale for design choices in the style of a research proposal.

\subsection{Purpose of the research and research questions}

Background. Electronic commerce provides an important new channel that connects the globe digitally for international commercial transactions. However, when we examine the progress of electronic commerce in developing countries, we find a different story. As Petrazzini and Kibati [30] note, "A closer look reveals great disparities between high- and low-income regions in terms of both Internet hosts and users. More than 97\% of all Internet hosts are in developed countries that are home to only $16 \%$ of the world's population." Numerous studies documenting the spread of the Internet in various parts of the world have highlighted the fact that Sub-Saharan Africa (SSA) is the region with the lowest level of economic, technological, and Internet development in the world [27].

Research questions and strategy. We wish to contribute to the growing body of work on the factors that affect the diffusion and expansion of information and communication technologies (ICTs), particularly the Internet, into SSA (see Mbarika [18] for a review of this). Specifically, the research study investigates the following questions:

RQ1. What kinds of physical, economic, and socio-political infrastructure are necessary for the establishment of viable e-commerce in SSA?

RQ2. What forms of e-commerce practices in SSA have the most potential for implementation in a period of three to ten years for maximal economic benefit?

RQ3. What practicable solutions are available for challenges in economic policy and managerial strategy regarding viable and beneficial e-commerce in SSA?

We adopt a research program consisting of a three-step strategy to investigate these questions. First, to identify factors that will answer the first two questions. This is largely subjective, as it depends on identifying plausible factors. The second step involves quantitatively testing the identified factors using a quasi-experimental design to verify if they are indeed pertinent. This is more objective and should provide more confidence and solid directions for the third step: offering practicable recommendations to address the third research question.

Scope of the initial study. We will address the first step of the research strategy: subjectively, identifying pertinent factors related to e-commerce infrastructure and practices. Extant academic literature provides some theoretical discussion related to the factors of importance in determining e-commerce diffusion in SSA and their relative importance [12,20,21,22,23,37,41]. However, obtaining a more comprehensive view necessitates perspectives from all four major stakeholders in e-commerce diffusion: practitioners, government officials, and officials of non-governmental organizations (NGOs), as well as academics engaged in e-commerce diffusion research $[19,38]$. 
Table 2

Comparison of traditional survey with Delphi method

\begin{tabular}{|c|c|c|}
\hline Evaluation criteria & Traditional survey & Delphi study \\
\hline $\begin{array}{l}\text { Summary of } \\
\text { procedure }\end{array}$ & $\begin{array}{l}\text { The researchers design a questionnaire with questions relevant to the } \\
\text { issue of study. There are numerous issues concerning validity of the } \\
\text { questions they must consider to develop a good survey. The } \\
\text { questionnaire can include questions that solicit quantitative or } \\
\text { qualitative data, or both. The researchers decide on the population } \\
\text { that the hypotheses apply to, and selects a random sample of this } \\
\text { population on whom to administer the survey. The respondents (who } \\
\text { are a fraction of the selected random sample due to non-response by } \\
\text { some) fill out the survey and return it. The researchers then analyze } \\
\text { the usable responses to investigate the research questions. }\end{array}$ & $\begin{array}{l}\text { All the questionnaire design issues of a survey also apply to a Delphi study. } \\
\text { After the researchers design the questionnaire, they select an appropriate } \\
\text { group of experts who are qualified to answer the questions. The researchers } \\
\text { then administer the survey and analyze the responses. Next, they design } \\
\text { another survey based on the responses to the first one and readministers it, } \\
\text { asking respondents to revise their original responses and/or answer other } \\
\text { questions based on group feedback from the first survey. The researchers } \\
\text { reiterate this process until the respondents reach a satisfactory degree of } \\
\text { consensus. The respondents are kept anonymous to each other (though not to } \\
\text { the researcher) throughout the process. }\end{array}$ \\
\hline $\begin{array}{l}\text { Representativeness } \\
\text { of sample }\end{array}$ & $\begin{array}{l}\text { Using statistical sampling techniques, the researchers randomly select } \\
\text { a sample that is representative of the population of interest. }\end{array}$ & $\begin{array}{l}\text { The questions that a Delphi study investigates are those of high uncertainty } \\
\text { and speculation. Thus a general population, or even a narrow subset of a } \\
\text { general population, might not be sufficiently knowledgeable to answer the } \\
\text { questions accurately. A Delphi study is a virtual panel of experts gathered to } \\
\text { arrive at an answer to a difficult question. Thus, a Delphi study could be } \\
\text { considered a type of virtual meeting or as a group decision technique, though } \\
\text { it appears to be a complicated survey. }\end{array}$ \\
\hline $\begin{array}{l}\text { Sample size for } \\
\text { statistical power and } \\
\text { significant findings }\end{array}$ & $\begin{array}{l}\text { Because the goal is to generalize results to a larger population, the } \\
\text { researchers need to select a sample size that is large enough to } \\
\text { detect statistically significant effects in the population. Power analysis } \\
\text { is required to determine an appropriate sample size. }\end{array}$ & $\begin{array}{l}\text { The Delphi group size does not depend on statistical power, but rather on } \\
\text { group dynamics for arriving at consensus among experts. Thus, the literature } \\
\text { recommends } 10 \text { to } 18 \text { experts on a Delphi panel. }\end{array}$ \\
\hline $\begin{array}{l}\text { Individual vs. group } \\
\text { response }\end{array}$ & $\begin{array}{l}\text { The researchers average out individuals' responses to determine the } \\
\text { average response for the sample, which they generalize to the } \\
\text { relevant population. }\end{array}$ & $\begin{array}{l}\text { Studies have consistently shown that for questions requiring expert judgment, } \\
\text { the average of individual responses is inferior to the averages produced by } \\
\text { group decision processes; research has explicitly shown that the Delphi } \\
\text { method bears this out. }\end{array}$ \\
\hline $\begin{array}{l}\text { Reliability and } \\
\text { response revision }\end{array}$ & $\begin{array}{l}\text { An important criterion for evaluating surveys is the reliability of the } \\
\text { measures. Researchers typically assure this by pretesting and by } \\
\text { retesting to assure test-retest reliability. }\end{array}$ & $\begin{array}{l}\text { Pretesting is also an important reliability assurance for the Delphi method. } \\
\text { However, test-retest reliability is not relevant, since researchers expect } \\
\text { respondents to revise their responses. }\end{array}$ \\
\hline Construct validity & $\begin{array}{l}\text { Construct validity is assured by careful survey design and by } \\
\text { pretesting. }\end{array}$ & $\begin{array}{l}\text { In addition to what is required of a survey, the Delphi method can employ } \\
\text { further construct validation by asking experts to validate the researcher's } \\
\text { interpretation and categorization of the variables. The fact that Delphi is not } \\
\text { anonymous (to the researcher) permits this validation step, unlike many } \\
\text { surveys. }\end{array}$ \\
\hline Anonymity & $\begin{array}{l}\text { Respondents are almost always anonymous to each other, and often } \\
\text { anonymous to the researcher. }\end{array}$ & $\begin{array}{l}\text { Respondents are always anonymous to each other, but never anonymous to } \\
\text { the researcher. This gives the researchers more opportunity to follow up for } \\
\text { clarifications and further qualitative data. }\end{array}$ \\
\hline Non-response issues & $\begin{array}{l}\text { Researchers need to investigate the possibility of non-response bias } \\
\text { to ensure that the sample remains representative of the population. }\end{array}$ & $\begin{array}{l}\text { Non-response is typically very low in Delphi surveys, since most researchers } \\
\text { have personally obtained assurances of participation. }\end{array}$ \\
\hline Richness of data & $\begin{array}{l}\text { The richness of data depends on the form and depth of the questions, } \\
\text { and on the possibility of follow-up, such as interviews. Follow-up is } \\
\text { often limited when the researchers are unable to track respondents. }\end{array}$ & $\begin{array}{l}\text { In addition to the richness issues of traditional surveys, Delphi studies } \\
\text { inherently provide richer data because of their multiple iterations and their } \\
\text { response revision due to feedback. Moreover, Delphi participants tend to be } \\
\text { open to follow-up interviews. }\end{array}$ \\
\hline
\end{tabular}




\subsection{Methodology}

\subsubsection{Selection of the Delphi methodology}

Although we could conduct a traditional survey to gather input from members of the major stakeholder groups concerning e-commerce infrastructure and practices in SSA, we judged the Delphi method to be a stronger methodology for a rigorous query of experts and stakeholders. Table 2 compares and contrasts the strengths and weaknesses of a Delphi study versus the traditional survey approach as a research strategy. In light of this comparison, we select the Delphi method for the following reasons:

1. This study is an investigation of factors that would support e-commerce in SSA. This complex issue requires knowledge from people who understand the different economic, social, and political issues there. Thus, a Delphi study answers the study questions more appropriately.

2. A panel study most appropriately answers the research questions, rather than any individual expert's responses. Delphi is an appropriate group method. Among other high-performing group decision analysis methods (such as nominal group technique and social judgment analysis [32]), Delphi is desirable in that it does not require the experts to meet physically, which could be impractical for international experts.

3. Although there may be a relatively limited number of experts with knowledge about the research questions, the Delphi panel size requirements are modest, and it would be practical to solicit up to four panels from 10 to 18 members in size [29].

4. The Delphi study is flexible in its design, and amenable to follow-up interviews. This permits the collection of richer data leading to a deeper understanding of the fundamental research questions.

5. We select the procedure for conducting Delphi studies outlined by Schmidt for the study because it would serve the dual purpose of soliciting opinions from experts and having them rank them according to their importance.

\subsubsection{Procedure for selecting experts}

Delbecq et al. provided detailed guidelines on how to solicit qualified experts for a nominal group technique study, making it clear that this procedure could also apply to a Delphi study. They described a rigorous procedure whose purpose was to ensure the identification of relevant experts and gave them the opportunity to participate in the study. A Delphi study does not depend on a statistical sample that attempts to be representative of any population. It is a group decision mechanism requiring qualified experts who have deep understanding of the issues. Therefore, one of the most critical requirements is the selection of qualified experts.

Panel Structure. We will divide experts into panels. Their size and constitution depends on the nature of the research question and the dimensions along which the experts will probably vary. In this case, four relevant categories of experts have important and valuable knowledge about e-commerce in SSA: academics, practitioners, government officials, and officials of nongovernmental organizations (NGOs). These groups probably would have somewhat different perspectives. Since it is a goal to obtain a reasonable degree of consensus, it would be best to have panels that separate these groups. This design also permits comparison of the perspectives 
of the different stakeholder groups. Following recommendations from Delphi literature, there will be 10 to 18 people in each panel. Within each panel, the goal is that at least half the members actually work in SSA. This structure will obtain a sufficient number of perspectives from the "inside," and we could perform analyses to see if there are differences in perspectives between respondents inside and outside. Figure 1 outlines the steps of our procedure for selecting experts.

\begin{tabular}{|c|c|}
\hline Step 1: Prepare KRNW & $\begin{array}{l}\text { - Identify relevant disciplines or skills: academics, practitioners, } \\
\text { government officials, and officials of NGOs } \\
\text { - Identify relevant organizations } \\
\text { - Identify relevant academic and practitioner literature }\end{array}$ \\
\hline $\begin{array}{l}\text { Step 2: Populate KRNW } \\
\text { with names }\end{array}$ & $\begin{array}{l}\text { - Write in names of individuals in relevant disciplines or skills } \\
\text { - Write in names of individuals in relevant organizations } \\
\text { - Write in names of individuals from academic and practitioner } \\
\text { literature }\end{array}$ \\
\hline $\begin{array}{l}\text { Step 3: Nominate } \\
\text { additional experts }\end{array}$ & $\begin{array}{l}\text { - } \text { Contact experts listed in KRNW } \\
\text { - } \quad \text { Ask contacts to nominate other experts } \\
\end{array}$ \\
\hline Step 4: Rank experts & $\begin{array}{ll} & \text { Create four sub-lists, one for each discipline } \\
\text { - } & \text { Categorize experts according to appropriate list } \\
\text { - } & \text { Rank experts within each list based on their qualifications } \\
\end{array}$ \\
\hline Step 5: Invite experts & $\begin{array}{l}\text { - Invite experts for each panel, with the panels corresponding to each } \\
\text { discipline } \\
\text { - Invite experts in the order of their ranking within their discipline sub- } \\
\text { list } \\
\text { - Target size is } 10-18 \\
\text { - Stop soliciting experts when each panel size is reached }\end{array}$ \\
\hline
\end{tabular}

Fig. 1. Procedure for selecting experts in the example study.

Identifying Experts. In alignment with the guidelines of Delbecq et al., the study will use a multiple-step iterative approach to identify the experts:

\subsubsection{Step 1. Prepare a Knowledge Resource Nomination Worksheet (KRNW)}

The purpose of the Knowledge Resource Nomination Worksheet is to help categorize the experts before identifying them, in order to prevent overlooking any important class of experts. Table 3 displays an initial Worksheet for the study. A research team of two academic researchers and one practitioner, all of whom are familiar with issues concerning the Internet in SSA, will fill in the KRNW. We will identify the most appropriate disciplines, organizations, and literature 
that would be most fruitful in identifying the world-class experts on the Internet and e-commerce in SSA. Delbecq et al. emphasized that it is important not to write down any specific names of experts at this stage. It is important to stay at a high level, first identifying classes of experts.

Table 3

\section{Sample Knowledge Resource Nomination Worksheet}

\begin{tabular}{|c|c|c|}
\hline Disciplines or Skills & Organizations & Related Literature \\
\hline 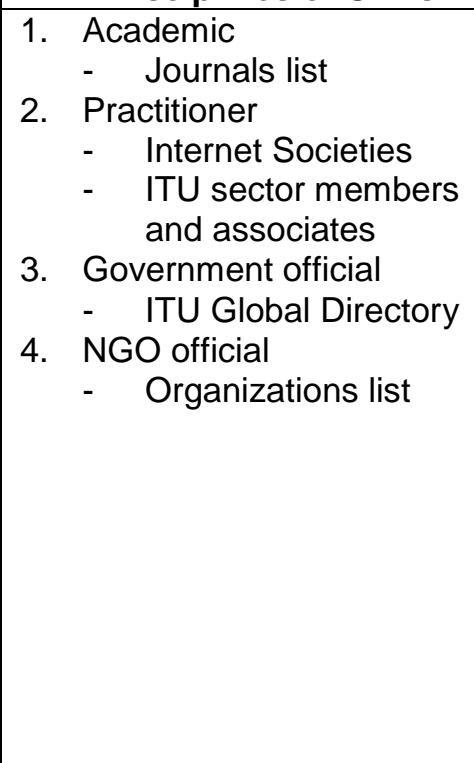 & $\begin{array}{ll}\text { 1. } & \text { World Bank } \\
\text { 2. United Nations Economic } & \text { Commission for Africa } \\
\text { 3. United Nations University } \\
\text { 4. Internet Societies in Africa } \\
\text { 5. African governmental } \\
\text { ministries of } \\
\text { telecommunications } \\
\text { 6. AFRIK-IT listserv }\end{array}$ & $\begin{array}{ll}\text { Academic: } \\
\text { 1. Review of African Political } \\
\text { Economy } \\
\text { 2. Journal of Management } \\
\text { Information Systems } \\
\text { 3. European Journal of } \\
\text { Information Systems } \\
\text { 4. Journal of Global Information } \\
\text { Management } \\
\text { 5. Journal of Global Information } \\
\text { Technology Management } \\
\text { 6. Electronic Journal of } \\
\text { Information Systems in } \\
\text { Developing Countries } \\
\text { Practitioner: } \\
\text { 1. Communications of the ACM } \\
\text { 2. Africa Business } \\
\text { 3. Proceedings of ITU Telecom }\end{array}$ \\
\hline
\end{tabular}

\subsubsection{Step 2. Populating the KRNW with names}

After the KRNW is completed, the following iterative procedure will be used to populate the categories with actual names of potential experts for the Delphi study. Each heading (disciplines, organizations, and literature) represents a different lens for identifying and considering experts, and it is expected that there will be a very high degree of overlap of expert names between and within headings. However, this multiple-lens perspective is necessary to identify as many experts as possible. For each category, we will first go through our personal list of contacts to fit as many names as we are able into the appropriate categories. This is the baseline procedure. However, the personal contacts of our research team, while extensive, are limited and biased to our personal networks. Thus, we will follow the procedure detailed by Delbecq et al. to ensure identification of the most qualified experts. After beginning with personal contacts, we will go through each heading in the KRNW and further populate the lists according to the categories. Each heading has a different general strategy:

Disciplines or skills. Each category will require a different approach for identifying experts:

1. Academics: We will populate this list almost entirely via a literature review of academic and practitioner journals under the "Related Literature" heading.

2. Practitioners: The first level of populating this list will involve contacting the various national chapters of the Internet Society in SSA. Currently, around 14 Sub-Saharan 
countries have chapters. The Internet Society chapters are expected to be a place where the local "movers and shakers" of Internet development congregate in their countries.

3. Government: We will use the International Telecommunication Union Global Directory to locate contact persons in the national ministries of telecommunications for each SubSaharan country. Ministers (secretaries) of telecommunications are considered very qualified experts, being in close contact with the most active and knowledgeable experts on the Internet in their countries.

4. NGOs: Numerous NGOs focus on the development of the Internet and ICTs in Africa. Two key places to begin looking for lists (other than Web searches) are with the United Nations Economic Commission for Africa and the World Bank's Information for Development program. These are ideal central resources, both because they are active NGOs themselves, they provide grants and other funding opportunities, and they sponsor conferences. Thus, they are in touch with the various NGOs that approach them for resources and networking. In addition, the ISWorld Developing Countries website has an extensive list of relevant NGOs.

Organizations. The Web, e-mail, phone, fax, or other pertinent methods will be the means of contacting the identified organizations. The objective is to contact people in these organizations who are experts themselves, and who can provide additional contacts within and outside their own organizations.

Related literature. We will review the academic and practitioner literature to locate all articles concerning the Internet or ICTs in SSA.

\subsubsection{Step 3. First-round contacts-Nominations for additional experts}

At this point, we will contact the identified experts and ask them to nominate others for inclusion on the list. We will provide a brief description of the Delphi study and explain that we have identified them as international experts on electronic commerce in SSA. Since this step does not solicit panelists for the final study, we will not invite individuals to participate in the study. Rather, we will tell the experts and contacts that the researchers are currently gathering biographical information on experts. We will obtain as much biographical information as possible about their qualifications. We will also track information about which contact refers which other experts, to facilitate the follow-up needed later. The first round of contacts aims primarily at extending the KRNW to ensure that it will include as many experts as can possibly be accessed.

For the organizations and literature that the contacts provide, we will follow the procedures detailed in Step 2 to identify specific names to place in the KRNW. Furthermore, we will need to obtain basic biographical information for every expert on the list in order to determine what qualifications they possess to make them experts. For example, the type of data recorded will include the number of papers published and presentations made, the length of years of e-commerce practice in SSA, number of years of tenure in government or NGO positions, etc. Adequate information on each expert is needed in order to rank their expertise for the next step. At the end of this step, we expect to have a list of about 200 experts.

\subsubsection{Step 4. Ranking experts by qualifications}

At this step, we will compare the qualifications of those on the large list of experts and rank them in priority for invitation to the study. First, we will create the four sub-lists: 
practitioners, government officials, NGO officials, and academics. Based on their qualifications, we will categorize experts into the sub-lists. As experts take on multiple roles, we may place an expert on more than one list. Next, each member of the research team will independently rank each sub-list, according to the person's degree of qualification. In these independent rankings, the rankers will use ties. We will then come together to reconcile the lists and create the four sub-lists as ranked by qualifications. Again, we will permit ties, since we will invite multiple panelists. Finally, we will invite the experts to participate in the study, stopping when we reach the required number.

\subsubsection{Step 5. Inviting experts to the study}

Based on the rankings, we will create one panel for each of the four categories. Again, the target panel size is 18 (10 minimum) with at least half the members having worked within SSA. Choosing the maximum number provides a buffer in case of attrition, even though participant drop-out tends to be very low when respondents have verbally assured their participation (contrast this with Brancheau et al.).

We will contact each panelist and explain the subject of the study and the procedures required for it, including the commitment required. For this study, we will ask panelists to commit to completing up to six 15-minute questionnaires and returning them within three days of receipt, for a total of one and a half hours over a period of one to three months. We will impose a limit of six questionnaires so as not to tax the participants, and yet give them an honest appraisal of their time commitment.

In this study, we will require participants to have access to e-mail, fax, or the Web for receiving and returning questionnaires. Normally, this might be a serious biasing factor. However, for a study employing experts on the use of electronic commerce, this is not an unreasonable requirement. Following the recommendation of Delbecq et al., the first questionnaire will be sent to each expert the same day they confirm their desire to participate.

For each sub-list, panelist solicitation will begin by inviting the top nine experts who work within SSA (half of our target of 18). Note that many of the experts will be based in North Africa and in South Africa, but these experts will not be included in this target quota. We will invite the experts one at a time until they reach the quota of nine. Next, we will invite the top nine experts in the remaining sub-list, whether or not they work in SSA.

The design of the five-step process will ensure the identification and invitation of the most qualified experts available.

There are several incentives that may lead experts to participate in a Delphi study where they might decline to participate in other studies: (1) being chosen in a diverse but selective group; (2) the opportunity to learn from the consensus building; and (3) increasing their own visibility in their organization and outside. These incentives can provide the strong inducements needed to attract busy experts.

\subsubsection{Data collection and analysis method}

Mechanism for administering the questionnaires. The Delphi questionnaires will be administered using e-mail, fax, and the Web. The panelists will be free to use whichever of these media was most convenient. The advantage of these "rapid" media is that they speed up the turnaround time between questionnaires. This is quite important using the Delphi method, which is notorious for the elapsed time required for data collection. Delbecq et al., for example, 
estimated that the average Delphi study could take 45 days to five months. This assumes a scenario where the panelists are all in one country, and the researchers rely on the postal system to deliver and return the questionnaires. However, in this case, the administration of the questionnaires is international. Assuming that a panelist in SSA filled out and returned a questionnaire immediately (probably an overly optimistic assumption), it would take about a month to receive the completed questionnaire for analysis, before the next one could be sent out. Considering that the researchers cannot send out the next questionnaire until all the results for a panel are in, such a lag time would be unreasonably long.

We will design three versions of each questionnaire: for e-mail, fax (which would be the most similar to a printed version), and the Web. As the questionnaires will be designed carefully following the principles of survey design (see Dillman [11]), the results are not expected to be significantly different from that by mail.

Administration procedure. Administration of the questionnaires will follow the procedure for "ranking-type" Delphi studies outlined by Schmidt. This will involve three general steps: 1) brainstorming for important factors; 2) narrowing down the original list to the most important ones; and 3) ranking the list of important factors.

\begin{tabular}{|c|c|}
\hline $\begin{array}{l}\text { Phase 1: } \\
\text { Brainstorming }\end{array}$ & $\begin{array}{l}\text { - } \quad \text { For this phase only, treat experts as individuals, not panels } \\
\text { - } \quad \text { Questionnaire 1: Ask experts to list relevant factors (not in any order) for } \\
\text { infrastructure and expediency lists } \\
\text { - } \quad \text { Consolidate these two lists from all experts, regardless of panel } \\
\text { - Remove exact duplicates, and unify terminology } \\
\text { - } \quad \text { Questionnaire 2: Send consolidated lists to experts for validation } \\
\text { - Refine final version of consolidated lists }\end{array}$ \\
\hline $\begin{array}{l}\text { Phase 2: Narrowing } \\
\text { down }\end{array}$ & $\begin{array}{l}\text { - Henceforth treat experts as four distinct panels } \\
\text { - } \quad \text { Questionnaire 3: Send infrastructure and expediency lists to each expert } \\
\text { - } \quad \text { Each expert selects (not ranks) at least ten factors on each list } \\
\text { - } \text { For each distinct panel, retain factors selected by over } 50 \% \text { of experts }\end{array}$ \\
\hline Phase 3: Ranking & $\begin{array}{l}\text { - } \text { Questionnaire 4: Ask experts to rank factors on each of their panel's } \\
\text { pared-down lists } \\
\text { - } \quad \text { Calculate mean rank for each item } \\
\text { - } \quad \text { Assess consensus for each list within each panel using Kendall's } W \\
\text { - Share feedback with each panelist and ask them to re-rank each list } \\
\text { - } \quad \text { Reiterate until panelists reach consensus or consensus plateaus } \\
\text { - } \quad \text { Final result is eight ranked lists, two for each panel }\end{array}$ \\
\hline
\end{tabular}

\section{Fig. 2. Delphi study administration process (adapted from [35]).}

General questionnaire design issues. For most of the design considerations, we will follow the guidelines put forth by Delbecq et al. and Dillman. First, considering that a Delphi study, with its multiple steps and iterations, is considerably more time-intensive for the respondents than a traditional survey, one objective will be to ensure that no single questionnaire should take more than 30 minutes to complete. Second, considering the administration mechanism of simultaneously employing e-mail, fax, and Web versions of the survey, it is 
critical that the researchers carefully design the surveys to ensure that these three formats were equivalent.

Adapted from Schmidt et al., Figure 2 outlines the process of administering the study.

\subsubsection{Administration Phase 1: Brainstorming}

Questionnaire 1: Initial collection of factors. We will send the first questionnaire on the same day that an expert agrees to serve on a Delphi panel using the expert's preference of e-mail, fax, or Web. The initial questionnaire for a Delphi survey is very simple, since it consists of an open-ended solicitation of ideas. The questionnaire will ask three basic questions, each corresponding to one of the research questions.

To address the first research question (RQ1), the questionnaire will ask experts to list at least six important factors (see Schmidt) affecting the establishing and growth of business use of the Internet in the countries of Sub-Saharan Africa. This question seeks to generate a list of infrastructure factors, which we refer to as the infrastructure list. To address the second research question (RQ2), the questionnaire will ask experts to list at least six e-commerce applications, practices, or features that practitioners could feasibly implement with beneficial effect within the next ten years in SSA. This question seeks to generate a second list of e-commerce practices, which we term the expediency list. Unlike the first two questions, simply asking the experts their recommendations as items, then ranking them will not appropriately address the third research question (RQ3). Recommendations are complex items that result as a composite and synergistic conclusion from the findings of the other questions. Thus, to answer this question at this stage, a third Delphi question that is closely related to the other two will be used: experts will be asked to offer a brief explanation (in two or three sentences for each factor) of the importance of each factor they have listed for the first two questions. These explanations will serve the dual purpose of providing a qualitative empirical basis for answering the third research question and helping us to understand and reconcile the various experts' factors. Moreover, the explanations will help to classify the factors into categories and will provide clarification for the next questionnaire, which renames and consolidates the factors.

We will send this questionnaire to all the experts without considering their panel at this phase and analyze the results from all experts together. Various studies have found that in group decision making, heterogeneous groups are more creative than homogeneous ones. The study design purposefully groups experts based on their homogeneity. However, by dividing the study into three phases, we will bypass this possibility of stifled creativity. The creative stage of the Delphi study occurs when soliciting factors from participants, while the ranking and weighting stages involve mainly judgmental opinion. This design does not use panels during the initial brainstorming stage, thus generating two lists of factors that represent the additive creativity of all the participants in the study, irrespective of their panels.

In analyzing the responses from the first questionnaire, we will first remove identical responses. At this time, we will record on the consolidated lists the number of panelists that initially suggests each item, and then group these factors conceptually into categories to make it easier for panelists to comprehend each list when returned for the next step. The grouping will be simply for presentation purposes and not for analysis, and we will base the categorizations on our knowledge of the issues concerning e-commerce in SSA (such as political, cultural, and economic issues).

Questionnaire 2: Validation of categorized list of factors. Since the researchers, rather than the experts, will perform the consolidation of the lists and grouping into categories, before 
proceeding, we will send a second questionnaire to validate the consolidated lists of factors. This questionnaire will list all the consolidated factors obtained from the first questionnaire, grouped into categories. In addition to a brief, one-sentence explanation of each factor, an explanatory glossary will be included to define and explain each factor, based on information provided by the experts in the first questionnaire. Furthermore, we will give experts an exact copy of their responses to the first questionnaire. The second questionnaire will ask experts to (a) verify that we have correctly interpreted their responses and placed them in an appropriate category; and (b) verify and refine the categorizations of the factors. According to Schmidt, "without this step, there is no basis to claim that a valid, consolidated list has been produced." At this time, experts will be able to suggest additional items that they might not have considered initially. Based on their responses, the two lists and categorizations will be further refined.

\subsubsection{Phase 2: Narrowing down factors}

The next two phases treat the experts as four distinct panels. In brief, panels will narrow down factors that reflect the perspectives of the constituent stakeholders (phase 2), and they then facilitate consensus (phase 3). In the second phase that narrows down the two lists of factors, our goal will be to understand the rating of importance of the factors based on the differing perspectives of various stakeholder groups. Certain groups of experts might assess the problems and opportunities for e-commerce in SSA somewhat differently, and these differences might have important implications for government policy and managerial action. Thus, the strategy is to have groups that think similarly decide among themselves which factors are the most important, rather than trying to reconcile significantly different perspectives.

Questionnaire 3: Choosing most important factors. We will then present the complete consolidated lists of items to each expert within each panel. The third questionnaire will be randomly arranged to cancel out bias in the order of listing of the items. Each panelist will be asked to select (not rank) at least ten factors on each list that they consider important to ecommerce in SSA. When all of the panelists have returned their responses, we will analyze each panel separately to identify the factors selected by over $50 \%$ of the experts in the panel; we will retain these factors for that panel. This process will reduce the lists to a manageable size. The target size for ranking will be no more than 20 to 23 items.

\subsubsection{Phase 3: Ranking relevant factors}

The goal of the final phase is to reach a consensus in the ranking of the relevant factors within each panel. Studies have consistently found that it is more difficult to reach consensus with Delphi groups than with ones that involve direct interaction between participants. However, with a panel design it is less difficult to attain consensus because the researchers deliberately select panel members for their homogeneity.

Questionnaire 4: Ranking the chosen factors. This phase of the procedure will involve each panel separately ranking the factors on each of their distinct pared-down lists. Each ranked list will reflect the priority order for the specific panel. In this phase, each expert will individually submit a rank ordering of the items: one ordering for each of the two listsinfrastructure and expediency. The questionnaire also will ask experts to submit comments explaining or justifying their rankings.

A review of the literature had not identified such an explanation of rankings in any

Delphi study, although Schmidt suggests soliciting helpful comments. Rohrbaugh compared the 
Delphi methodology with a group decision method based on social judgment analysis (SJA), which uses a formal graphical method to present the reasoning behind a panelist's decisions to the other members of the panel. Although the results using SJA were not significantly more accurate, the groups reached a higher degree of consensus, since the members understood one another's reasoning. Based on Rohrbaugh's study, the panels should arrive at consensus more quickly if provided with some sort of feedback about the panelists' reasonings.

When it comes to quantitatively determining the ranks of the items in the lists, Schmidt provided an excellent and detailed guideline of principles to follow, which we will use as the basis of our methodology here. There are a number of different metrics for measuring nonparametric rankings [36], but Kendall's $W$ coefficient of concordance is widely recognized as the best. The value of $W$ ranges from 0 to 1, with 0 indicating no consensus, and 1 indicating perfect consensus between lists. Schmidt provided a table for interpreting different values of $W$, with 0.7 indicating strong agreement. After calculating the concordance within each panel, the $W$ value suggests how to proceed in the ranking. A $W$ value of 0.7 or greater would indicate satisfactory agreement, and we would consider the ranking phase completed. We could use mean rankings for each item to compute the final ranking for a completed panel.

However, if $W$ is less than 0.7 , the ranking questionnaire must be resent to the members of that panel. Each reiteration would return the items for the panel, listed in order of mean ranks. For each item, we will give the panelists the following information to help them revise their rankings: (1) the mean rank of the item for the panel; (2) the panelist's ranking of the item in the former round; (3) an indication of the current level of consensus, based on the value of $W$ (for example, "weak agreement"); and (4) a paragraph summarizing the other panelists' comments on why they ranked that item as they did. Based on this, we will ask the panelists to revise their rankings for each item, again asking them to explain their rankings and revisions.

We will reiterate this ranking process until we reach one of three stopping criteria: (1) $W$ reaches a value of 0.7 , indicating a satisfactory level of concordance. (2) We reach the third iteration, which would be the sixth questionnaire that a panelist received for this study, per our original promise. However, on the third iteration, we will ask panelists if they were willing to continue iterating until they reached consensus. If enough panelists agree, we will continue the process until $W$ rises to the desired level. (3) Following Schmidt's suggestion, we will stop iterating if the mean rankings for two successive rounds is not significantly different. We could measure this difference using the McNamar test, which "is typically used in a repeated measures situation in which each subject's response is elicited twice (pre-post test)" [3].

At the end of this ranking phase, we will have eight ranked lists - two from each of the four panels - representing the priorities that each of the panels placed on various factors in affecting the practice of e-commerce in SSA. This rigorous process assures that the factors in the list are the most important, and that the rankings are a valid indicator of the relative importance of the various factors. Based on these results, we will be able to reassess our theoretical observations from the literature and offer propositions on expected relationships between factors in affecting e-commerce in SSA.

\section{Conclusion: Uses of the Delphi method for theory building}

As shown in Table 4, the Delphi method is a versatile research tool that researchers can employ at various points in their research. 


\section{Table 4}

\section{Applications of the Delphi method in the research process}

- Identification of the research topic

- Specification of research question(s)

- Identification of a theoretical perspective for the research

- Selection of variables of interest/generation of propositions

- Preliminary identification of causal relationships

- Definition of constructs and creation of a common language for discourse

Use of the Delphi method for forecasting and issue identification/prioritization can be valuable in the early stages, particularly in selecting the topic and defining the research question(s). A major contribution of the MISRC/SIM studies of key managerial IS concerns, published in MIS Quarterly, [5], for example, was to provide IS researchers with an understanding of the most critical issues in IS management as seen by practicing IS executives, thus contributing to the relevance of IS research to practitioners. The ranked issues in these studies represented broad topic areas (e.g., "Building a responsive IT infrastructure") for future research. In Delphi studies where the questions posed to experts are narrower and more specific in terms of subject, the resulting ranked lists can guide the framing of specific questions. For example, the top ranked software project risk factor identified in the study by Schmidt et al."Lack of top management commitment" - could stimulate the formation of specific research questions related to this particular issue. Another risk factor identified in the Schmidt et al. study, "Conflict between user departments," points to the body of theoretical work related to situations of conflict that arise when groups seek to preserve their vested interests (e.g., [26,31]) as a useful lens for investigation of this issue.

Researchers can use the Delphi method in a number of ways related directly to theory building. First, the ranking of a Delphi study can be of value in the initial stages of theory development-helping researchers to identify the variables of interest and generate propositions. For example, the study described in the previous section would not only identify what factors experts perceive are important for e-commerce in Africa, but which ones are viewed as more important than others. In any study, researchers must select a parsimonious list of relevant variables. The experts' rankings prioritize the perceived effects of factors, and help the researchers to select the factors with the strongest effects.

Second, additional advantages are possible up to the extent of generalizability of resulting theory. Because a Delphi study solicits information from experts who have a wide range of experience, by inquiring about their experiences and opinions researchers significantly extend the empirical observations upon which their initial theory is based - thus strengthening the grounding of the theory and increasing the likelihood that the resulting theory will hold across multiple contexts and settings.

A third benefit to theory building derives from asking experts to justify their reasoning. This is an optional feature of Delphi studies; the very first Delphi study conducted by Dalkey used it. Although not many recent Delphi studies have taken advantage of this option, asking respondents to justify their responses can be valuable aid to understanding the causal relationships between factors, an understanding that is necessary to build theory. 
Fourth, a Delphi study can contribute to construct validity. Construct validity relies on a clear definition of the construct. Delphi study designs, such as the example study, that ask participants to validate their initial responses to make sure that that the researchers understand the meanings of the list items submitted could contribute towards this goal. In addition, the framing of construct definitions in alignment with definitions in common use by practitioners also contributes towards consistency in the understandings of the construct by participants in future studies as well as understandability by practitioners of the resulting theory. One of the contributions of the Delphi study by Holsapple and Joshi, for example, is that it provides a common language for discourse about knowledge management.

Although theory-building has not been the main focus of much of the Delphi research, a carefully designed study can not only be valuable for developing theory, but it can produce relevant theoretical research. Delphi studies, then, can contribute directly and immediately to both theory and practice. They build theory by the design and rigor of the study, whereas practitioners will immediately have available to them lists of prioritized critical factors, generated by experts, which they could apply to their individual situations.

The discussion in this section highlights the versatility of the Delphi method as a research tool-a tool particularly well suited to new research areas and exploratory studies. Through this discussion and detailed example of a Delphi study design, we hope to heighten awareness of the utility of the method for different purposes the theory-building process. In conclusion, we encourage researchers to consider incorporating this tool in their personal repertoire of research methods so that it is available to them to use as needed to accomplish their research objectives.

\section{Acknowledgements}

We thank Victor Mbarika for his help in the e-commerce study that we used as an illustrative framework for this paper. We also thank Casey Cegielski for his valuable references that gave us a literature base to study the Delphi method. 


\section{References}

[1] R.H. Ament, Comparison of Delphi forecasting studies in 1964 and 1969, Futures March, 1970, p. 43.

[2] D. Bacon, B. Fitzgerald, A systemic framework for the field of information systems, Database for Advances in Information Systems 32 (2), 2001, pp. 46-67.

[3] N.H. Barry, Nonparametric statistics, http://faculty-staff.ou.edu/B/Nancy.H.Barry1/nonpar.html, 2002.

[4] J.C. Brancheau, B.D. Janz, J.C. Wetherbe, Key issues in information systems management: 1994-95 SIM Delphi results, MIS Quarterly 20 (2), 1996, pp. 225-242.

[5] J.C. Brancheau, J.C. Wetherbe, Key issues in information systems management, MIS Quarterly 11 (1), 1987, pp. 23-45.

[6] C.G. Cegielski, A Model of the Factors that Affect the Integration of Emerging Information Technology Into Corporate Strategy, unpublished Doctoral Dissertation, University of Mississippi, 2001.

[7] M.R. Czinkota, I.A. Ronkainen, International business and trade in the next decade: Report from a Delphi study, Journal of International Business Studies 28 (4), 1997, pp. 827-844.

[8] N. Dalkey, O. Helmer, An experimental application of the Delphi method to the use of experts, Management Science 9 (3), 1963, pp. 458-467.

[9] A.L. Delbecq, A.H. Van de Ven, D.H. Gustafson, Group techniques for program planning: A guide to nominal group and Delphi processes, Scott, Foresman and Company, Glenview, Illinois, 1975.

[10] N. Denzin, Y. Lincoln, Entering the field of qualitative research, in: N. Denzin, Y. Lincoln (Eds.), The Landscape of Qualitative Research, SAGE, Thousand Oaks, California, 1998, pp. 1-34.

[11] D.A. Dillman, Mail and Internet surveys: The Tailored Design Method, John Wiley \& Sons, New York, 2000.

[12] A. Dutta, The physical infrastructure for electronic commerce in developing nations: Historical trends and the impact of privatization, International Journal of Electronic Commerce 2 (1), 1997, pp. 61-83.

[13] S. Hayne, C. Pollard, A comparative analysis of critical issues facing Canadian information systems personnel: A national and global perspective, Information \& Management 38 (2), 2000, pp. 73-86.

[14] P. Holsapple, K. Joshi, Knowledge manipulation activities: Results of a Delphi study, Information \& Management 39 (6), 2002, pp. 477-490.

[15] J.E. Kendall, K.E. Kendall, S. Smithson, I.O. Angell, SEER: A divergent methodology applied to forecasting the future roles of the systems analyst, Human Systems Management 11 (3), 1992, pp. 123-135. 
[16] V. Lai, W. Chung, Managing international data communications, Information \& Management 45 (3), 2002, pp. 89-93.

[17] H.A. Linstone, M. Turoff, The Delphi Method: Techniques and Applications, AddisonWesley Publishing Company, London, 1975.

[18] V.W.A. Mbarika, Africa's Least Developed Countries' Teledensity Problems and Strategies, ME \& AGWECAMS Publishers, Yaoundé, Cameroon, 2001.

[19] V.W.A. Mbarika, T.A. Byrd, P. McMullen, P. Musa, Teledensity growth constraints and strategies for Africa's LDCs: "Viagra" prescriptions or sustainable development strategy?, Journal of Global Information Technology Management 5 (1), 2002, p. 25-42.

[20] V.W.A. Mbarika, T.A. Byrd, J. Raymond, Growth of teledensity in least developed countries: Need for a mitigated euphoria, Journal of Global Information Management 10 (2), 2002, pp. 14-27.

[21] R. Montealegre, Implications of electronic commerce for managers in less-developed countries, Information Technology for Development 7 (3), 1996, pp. 145-152.

[22] R. Montealegre, Managing information technology in modernizing "against the odds": Lessons from an organization in a less-developed country, Information \& Management 34, 1998, pp. 103-116.

[23] R. Montealegre, Four visions of e-commerce in Latin America in the year 2010, Thunderbird International Business Review 43 (6), 2001, pp. 717-735.

[24] P. Mulligan, Specification of a capability-based IT classification framework, Information \& Management 39 (8), 2002, pp. 647-658.

[25] S. Nambisan, R. Agarwal, M. Tanniru, Organizational mechanisms for enhancing user innovation in information technology, MIS Quarterly 23 (3), 1999, pp. 365-395.

[26] V.K. Narayanan, L. Fahey, The micro-politics of strategy formulation, Academy of Management Review 7, 1982, pp. 25-34.

[27] M. Odedra, M. Lawrie, M. Bennet, S.E. Goodman, Sub-Saharan Africa: A technological desert, Communications of the ACM 36 (2), 1993, pp. 25-29.

[28] R. Ono, D.J. Wedemeyer, Assessing the validity of the Delphi technique, Futures 26, 1994, pp. 289-305.

[29] S.J. Paliwoda, Predicting the future using Delphi, Management Decision 21 (1), 1983, pp. 31-38.

[30] B. Petrazzini, M. Kibati, The Internet in developing countries, Communications of the ACM 42 (6), 1999, pp. 31-36.

[31] J. Pfeffer, Managing with Power: Politics and Influence in Organizations, Harvard Business School Press, Boston, 1992.

[32] J. Rohrbaugh, Improving the quality of group judgments: Social judgment analysis and the Delphi technique, Organizational Behavior and Human Performance 24, 1979, pp. 73-92.

[33] G. Rowe, G. Wright, F. Bolger, Delphi: A re-evaluation of research and theory, Technological Forecasting and Social Change 39, 1991, pp. 235-251. 
[34] R.C. Schmidt, Managing Delphi surveys using nonparametric statistical techniques, Decision Sciences 28 (3), 1997, pp. 763-774.

[35] R.C. Schmidt, K. Lyytinen, M. Keil, P. Cule, Identifying software project risks: An international Delphi study, Journal of Management Information Systems 17 (4), 2001, pp. 5-36.

[36] S. Siegel, N.J. Castellan, Jr., Nonparametric Statistics for the Behavioral Sciences, McGraw Hill, New York, 1988.

[37] B. Travica, Diffusion of electronic commerce in developing countries: The case of Costa Rica, Journal of Global Information Technology Management 5 (1), 2002, pp. 4-24.

[38] UNECA, The process of developing national information and communications infrastructure (NICI) in Africa, http://www.uneca.org/adf99/nici.htm, 1999.

[39] D. Viehland, J. Hughes, The future of the wireless application protocol, Proceedings of the Eighth Americas Conference on Information Systems, Dallas, 2002, pp. 1883-1891.

[40] K. Weick, Organizational redesign as improvisation, in G. Huber, W. Glick, eds., Organizational Change and Redesign: Ideas and Insights for Improving Performance, Oxford University Press, New York, NY, 1993, pp. 346-379.

[41] P. Wolcott, L. Press, W. McHenry, S.E. Goodman, W. Foster, A framework for assessing the global diffusion of the Internet, Journal of the Association for Information Systems 2 (6), 2001. 
Chitu Okoli is an assistant professor in the Department of Decision Sciences and Management Information Systems of the John Molson School of Business at Concordia University, Montréal, Canada. He obtained a PhD in 2003 from the Department of Information Systems and Decision Sciences at Louisiana State University, USA. He primarily researches applications of the Internet in developing countries, and strategically using the Internet for competitive advantage. In addition to the Delphi method, Chitu Okoli also uses quantitative surveys and stochastic simulation.

Suzanne Pawlowski is an Assistant Professor in the Department of Information Systems and Decision Sciences at Louisiana State University. She holds a Ph.D. degree in Computer Information Systems from Georgia State University and M.B.A. and B.A. degrees from the University of California, Berkeley. Research interests include enterprise systems and organizational learning, retention of IT professionals, and collaborative visualization technologies. Scholarly publications include papers in ACM Computing Surveys, Communications of the ACM, IEEE Transactions on Software Engineering, and Communications of AIS. Her previous work experience includes a 20 -year career in IT at Lawrence Livermore National Laboratory, including manager of application development. 